\title{
Conjugated and Unconjugated Plasma Androgens in Normal Ghildren
}

\author{
Donald A. Boon, ${ }^{291}$ Raymond E. Keenan, W. Roy Slatnwhite, Jr., and Thomas Aceto, Jr.
}

Children's Hospital, Medical Foundation of Buffalo, Roswell Park Memorial Institute, and Departments of Biochemistry and Pediatrics, School of Medicine, State University of New York at Buffalo, Buffalo, New York, LS.1

\section{Extract}

Methods developed in this laboratory permit measurement of the androgens, testosterone $(\mathrm{T})$, dehydroepiandrosterone (I)), and androstenedione $(\Delta)$ on a $10-\mathrm{ml}$ sample of plasma. We have determined concentrations of the unconjugated androgens ( $\mathrm{T}, \Delta$, D) as well as of the sulfates of dehydroepiandrosterone (DS) and androsterone (AS) in the plasma of 85 healthy children of both sexes from birth through the age of 20 years. Our results are shown and summarized, along with those of other investigators.

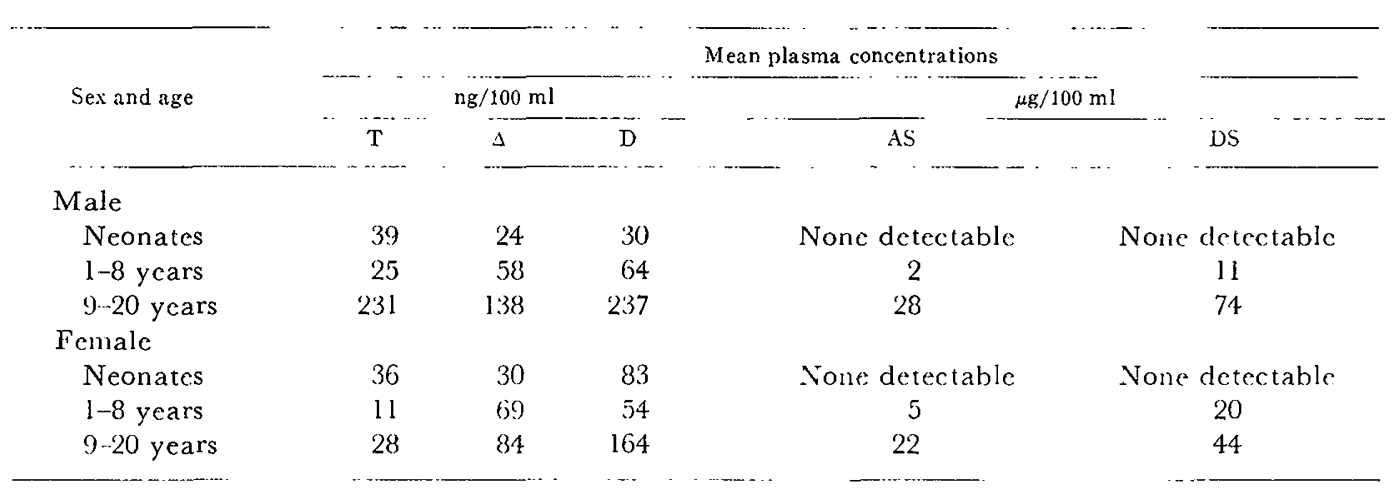

'Testosterone was elevated in both sexes in the newborn as compared with the 1-8year-old group. In contrast, sulfated androgens, with one exception, were undetectable early in life. In males, there was a marked rise in all androgens, especially $\mathrm{T}$, in the 9-18-year-old group. The increase in plasma androgens occurred before clinical manifestations of increased androgens became evident. In females, there was only a modest increase in plasma androgens in the 9-18-year-old group except in the case of $\Delta$ which did not change. The greatest increases were in D, DS and AS. This is the first report of unconjugated androgen concentrations in the adolescent female.

\section{Speculation}

Measurement of the plasma androgens will aid in evaluation of children with sexual infantilism or sexual precocity. The prepubertal rise in plasma testosterone in males may be accompanied by a higher level of plasma protein binding than that which is found after puberty becomes evident. 


\section{Introduction}

Until recently evaluation of androgen secretion has been limited to physical examination and measurement of 24-hr excretion in urine of 17-ketosteroids, the metabolites principally of the weaker androgens. Other procedures not yet in routine general use, which are somewhat more specific, involve the measurement of specific steroids in 24-hr urine specimens. Methods developed in this laboratory $[19,21]$ permit measurcment of the androgens, testosterone $(\mathrm{T})$, dehydroepiandrosterone (D), and androstenedione $(\Delta)$ on a $10-\mathrm{ml}$ sample of plasma. We have determined concentrations of the unconjugated androgens $(T, \Delta, D)$ as well as of the sulfates of dehydroepiandrosterone (DS) and androsterone (AS) in the plasma of 85 healthy children of both sexes from birth through the age of 20 years since we anticipate that the measurement of these substances will aid in the evaluation of children with sexual infantalism or sexual precocity.

\section{Materials and Methods}

\section{Unconjugated Androgen Determination}

The double isotope derivative method, using ${ }^{14} \mathrm{C}$ as the reference isotope and ${ }^{82} \mathrm{Br}$ as the measuring isotope first described by Slaunwhite and Neely [21] and its application to androgens as described by Saroff et al. [19], was used.

Epitestosterone, if present, is separated by chromatography before labeling with ${ }^{82} \mathrm{Br}$ and would, therefore, not be detected. The specific activity of the brominated derivative varied between $400 \mathrm{cpm} / \mathrm{m} \mu \mathrm{g}$ and $2500 \mathrm{cpm} / \mathrm{m} \mu \mathrm{g}$ with blank values of about $50 \mathrm{cpm}$. This procedure would thus allow quantitation clown to $1 \mathrm{ng} / 100 \mathrm{ml}$ plasma inasmuch as recoveries averaged about $20 \%$ overall.

\section{Collection of Plasma Samples}

Approximately $20 \mathrm{ml}$ whole blood were drawn from each subject into heparinized tubes. The plasma was separated and frozen until analysis. In some cases in which only small amounts of whole blood could be obtained, as in the 1-5-day-old children, plasma samples were pooled prior to analysis. The subjects or their parents, or both, were informed of the purpose of the project and consent was obtained for withclrawing blood samples for analysis.

\section{Conjugated Androgen Determination}

A tritium-labeled internal standard of DS (10 nCi) was added to the methylene chloricle-extracted aqueous residue of $5 \mathrm{ml}$ plasma which was adjusted to $\mathrm{pH} 1.0$ with $65 \%$ sulfuric acid. After dissolving $70 \%$ $\mathrm{w} / \mathrm{v}$ ammonium sulfate in the plasma. the solution was extracted twice with 2 vol tetrahydrofuran (THF), which had been redistilled from potassium hydroxide pellets. After addition of $0.2 \mathrm{ml} 70 \%$ perchloric acid, the solution was allowed to incubate at $50^{\circ}$ for $3 \mathrm{hr}$. Three milliliters water were then added, and the solution was extracted with $20 \mathrm{ml}$ acid-washed and redistilled heptane. The aqueous layer was discarded, as were the subsequent washes of $8 \mathrm{ml} 10 \%$ sodium hydroxide and $8 \mathrm{ml}$ water.

The heptane-soluble residue, dissolved in $6 \mathrm{ml} 70 \%$ methanol, was washed three times with 9-ml aliquots of heptane. After the addition of $6 \mathrm{ml}$ water, the aqueous methanol was extracted twice with $15 \mathrm{ml}$ benzene which hacl been freshly purified by sulfuric acid extraction and redistillation. The residue of the benzene extract was dissolved in $1.0 \mathrm{ml}$ benzene; $0.1 \mathrm{ml}$ of this solution was counted in a liquid-scintillation spectrometer to determine recovery and $0.5 \mathrm{ml}$ was evaporated for gas chromatography using flame ionization detection.

Pregnenolone (1250 ng) was added as an internal standard. To the residue was added $25 \mu$ liters of a solution of $N$, O-bis-(trimethylsilyl)acetamide (BSA) in acetonitrile [20, 21]. After more than $5 \mathrm{~min}$ at room temperature, 1 pliter of this solution was injected into a $1 / 4$-inch $\times 6$-foot glass column containing $1 \% \mathrm{OV}$ - 1 Chromosorb Gr (100-120 mesh). At $200^{\circ}$ the retention times were as follows: $\mathrm{D}, 2.2 \mathrm{~min}$; androsterone (AN) and etiocholanolone, $2.8 \mathrm{~min}$; and pregnenolone $(\mathrm{P})$, $4.5 \mathrm{~min}$. The ratio of peak heights $(\mathrm{D} / \mathrm{P}=r$ or $\mathrm{AN} /$ $\mathrm{P}=r^{\prime}$ ) was calculated, and the mass of $\mathrm{D}$ or $\mathrm{AN}$ was read from calibration curves $(y(n g)=26.3 r \pm 2.1 y$ $\left.(n g)=29.4 r^{\prime}+1.8\right)$. The androsterone peak was approximately $1.9 \mathrm{~cm} / 10 \mathrm{ng}$ and the dehydroepiandrosterone peak was $2.4 \mathrm{~cm} / 10 \mathrm{ng}$. Therefore, assuming a $70 \%$ overall recovery and the limit of cletection of peak height of $0.5 \mathrm{~cm}$, the lowest plasma concentration accurately measurable using this method would be $4 \mu \mathrm{g}$ / $100 \mathrm{ml}$ for AS and $3 \mu \mathrm{g} / 100 \mathrm{ml}$ for DS. Concurrently, blank samples showed no peaks in the areas mentioned nor were any peaks seen in samples reported as NI) (none detectable).

The present method for the quantitation of DS and AS in plasma is simpler than existing procedures $[9$, $15,17,18,20,23]$ because of exclusion of one or more chromatographic steps prior to gas chromatography. Aclequate resolution from interfering material was obtained in nearly every instance provided the solvents 
were purified as described. Because OV-I does not resolve androsterone and etiocholanolone, the AS values will include any etiocholanolone sulfate. The latter is usually negligible in adults, but has not been determined in children. Isoandrosterone $(3 \beta, 5 \alpha)$, if present, would also be measured as AS.

\section{Statistical Analysis of Data}

The data obtained (Tables I and II) show, in many cases, an extremely skewed distribution with the maximum frequency often falling in the $0-25 \mathrm{ng} / 100 \mathrm{ml}$ area and the rest of the values strung out over a very wide range. In such circumstances, when there is no gaussian distribution, conventional statistical parameters, such as standard deviation and standard error of the mean, lose their meaning. Even the calculation of "mean" values is misleading, because one value may unduly influence the mean. For example, one determination of $\mathrm{T}(139 \mathrm{ng} / 100 \mathrm{ml}$; see Table I) is responsible for more than $50 \%$ of the mean $T$ value (Table IrI) of the 1-8-year-old male group. We can find no clinical or procedural reason for eliminating such "far-out" values. It is interesting that the females are less prone to such extreme values. Inasmuch as unpublished data on normal adult males obtained in this laboratory indicate that androgen concentrations may vary by a factor of 5 to 10 at different times of the day, but without following a regular circadian rhythm, the collation of data from many individuals will result in a realistic pattern of plasma concentrations.

One useful artifice for obtaining a more representative set of values simply excludes the "tails" of the distribution; it is readily applicable to skewed distributions. Thus, we have reported the median $50 \%$ range. We believe that this is more significant than the mean because extreme values, for whatever cause, have been excluded. For example, in 6 of 20 sets of values, the mean is greater than the median $50 \%$ range (Table III) and in several others, it lies close to the upper limit of the median $50 \%$ range.

\section{Results}

Our results are shown in Tables I and II and are summarized, along with those of other investigators, in Table III and Figure 1. Testosterone was elevated in both sexes in the newborn as compared with the 1-8year-old group. In contrast, sulfated androgens, with one exception, were undetectable early in life.

In males, there was a marked rise in all androgens, especially $T$, in the $9-18$-year-old group. The increase in plasma androgens occurred before clinical manifestations of increased androgens became evident. This, however, was not always true, as some of the older teenagers had low values for one or more of the hor-

Table $I$. Individual plasma androgen concentrations in male children ${ }^{1}$

\begin{tabular}{|c|c|c|c|c|c|}
\hline Age, yr & $\underset{\mathrm{ng} / 100 \mathrm{ml}}{\mathrm{T}}$ & $\stackrel{\Delta,}{\mathrm{ng} / 100 \mathrm{ml}}$ & $\underset{\mathrm{ng} / 100 \mathrm{ml}}{\mathrm{D}}$ & $\underset{\mu \mathrm{g} / 100 \mathrm{ml}}{\mathrm{AS}}$ & $\underset{\mu \mathrm{g} / 100 \mathrm{ml}}{\mathrm{DS}}$ \\
\hline 2 days $^{2}$ & $\mathrm{ND}^{3}$ & 22 & $\mathrm{ND}$ & ND & 125 \\
\hline 3 days $^{2}$ & 98 & 25 & 28 & ND & ND \\
\hline 5 days $^{2}$ & 19 & 25 & 62 & & \\
\hline 1 & ND & 2 & $\mathrm{ND}$ & $\mathrm{ND}$ & ND \\
\hline 1.5 & 62 & 55 & 287 & & \\
\hline 4 & 139 & 15 & ND & ND & 18 \\
\hline 5 & 16 & 76 & 21 & 4 & 21 \\
\hline 6 & 38 & 18 & ND & 8 & 23 \\
\hline 6 & ND & 339 & ND & ND & 16 \\
\hline 7 & 15 & 21 & 62 & 5 & 14 \\
\hline 7 & ND & 20 & ND & ND & ND \\
\hline 7 & ND & 9 & 246 & ND & ND \\
\hline 8 & ND & 16 & 61 & 4 & 18 \\
\hline 8 & ND & 70 & 28 & ND & ND \\
\hline 9 & 32 & 430 & 1790 & & \\
\hline 9 & 178 & 203 & 7 & & \\
\hline 9 & 29 & ND & 40 & & \\
\hline 10 & & 52 & 10 & & \\
\hline 10 & 55 & & 2014 & & \\
\hline 11 & 293 & 40 & ND & ND & ND \\
\hline 12 & 276 & 83 & ND & ND & ND \\
\hline 12 & 1078 & 226 & 166 & 60 & 66 \\
\hline 12 & $\mathrm{ND}$ & 256 & 56 & $\mathrm{ND}$ & 29 \\
\hline 12 & 27 & 176 & 564 & 11 & 80 \\
\hline 13 & 87 & 98 & 159 & 123 & 228 \\
\hline 13 & 902 & ND & 113 & 34 & 17 \\
\hline 13 & 82 & 44 & 61 & 81 & 105 \\
\hline 13 & ND & 21 & 18 & & \\
\hline 13 & 245 & 197 & 217 & & \\
\hline 14 & 16 & $\mathrm{ND}$ & 127 & 44 & 78 \\
\hline 14 & 636 & 78 & 244 & $\mathrm{ND}$ & 74 \\
\hline 14 & 441 & 54 & 31 & ND & 115 \\
\hline 14 & 202 & ND & & & \\
\hline 15 & 235 & 25 & 318 & 29 & 67 \\
\hline 16 & 394 & 88 & 268 & 10 & 74 \\
\hline 16 & 350 & 138 & 524 & & \\
\hline 16 & ND & $6 \mathrm{I}$ & 273 & & \\
\hline 17 & & 44 & 19 & 20 & 58 \\
\hline 18 & 111 & ND & 199 & 39 & 242 \\
\hline 19 & & 15 & 27 & 30 & 57 \\
\hline 19 & 8 & 19 & 104 & & \\
\hline 20 & 102 & 1250 & 56 & & \\
\hline
\end{tabular}

$1 \mathrm{~T}$ : testosterone. $\Delta$ : androstenedione. $\mathrm{D}$ : dehydroepiandrosterone. AS : androsterone sulfate. DS: dehydroepiandrosterone sulfate.

${ }^{2}$ A pool of several plasmas.

${ }^{3} \mathrm{ND}$ : none detectable. 
mones. These subjects had normal sexual development.

In females, there was only a modest increase in

Table $I I$. Individual plasma androgen concentrations in female children ${ }^{1}$

\begin{tabular}{|c|c|c|c|c|c|}
\hline Age, yr & $\stackrel{\mathrm{T}}{\mathrm{ng} / 100 \mathrm{ml}}$ & $\begin{array}{c}\Delta, \\
\mathrm{ng} / 100 \mathrm{ml}\end{array}$ & $\begin{array}{c}\mathrm{D} \\
\mathrm{ng} / 100 \mathrm{ml}\end{array}$ & $\underset{\mu \mathrm{g} / 100 \mathrm{ml}}{\mathrm{AS}}$ & $\underset{\mu \mathrm{g} / 100 \mathrm{ml}}{\mathrm{DS}}$ \\
\hline 1 day $^{2}$ & & 19 & 70 & & \\
\hline l day ${ }^{2}$ & 40 & 48 & 31 & $\mathrm{ND}^{3}$ & ND \\
\hline 5 days $^{2}$ & 38 & 47 & 91 & ND & ND \\
\hline 5 days $^{2}$ & 29 & 4 & 141 & & \\
\hline 2 & 55 & 157 & 137 & ND & $\mathrm{ND}$ \\
\hline 3 & & 77 & 5 & ND & ND \\
\hline 4 & 10 & ND & 67 & $\mathrm{ND}$ & ND \\
\hline 4 & ND & 2 & ND & $<4$ & 16 \\
\hline 5 & 25 & ND & ND & ND & 46 \\
\hline 6 & ND & 192 & ND & 5 & 6 \\
\hline 6 & ND & 15 & ND & ND & 27 \\
\hline 6 & 24 & 46 & 226 & & \\
\hline 7 & 15 & 43 & 106 & 47 & 102 \\
\hline 7 & ND & 1 & ND & ND & ND \\
\hline 7 & ND & $\mathrm{ND}$ & 117 & ND & ND \\
\hline 8 & ND & 348 & 38 & $\mathrm{ND}$ & 30 \\
\hline 8 & 3 & 18 & 2 & $<4$ & 11 \\
\hline 9 & ND & 275 & 37 & 75 & $\mathrm{ND}$ \\
\hline 9 & ND & 64 & 15 & 15 & 10 \\
\hline 10 & 8 & 102 & ND & 10 & 26 \\
\hline 10 & ND & 44 & 88 & ND & 43 \\
\hline 11 & ND & ND & 228 & $\mathrm{ND}$ & 39 \\
\hline 11 & & 47 & 53 & 48 & 74 \\
\hline 12 & 29 & 7 & 85 & ND & 47 \\
\hline 12 & 2 & 4 & 104 & 28 & 68 \\
\hline 12 & ND & 71 & 37 & ND & 7 \\
\hline 13 & $\mathrm{ND}$ & 534 & 146 & $\mathrm{ND}$ & ND \\
\hline 13 & 22 & 36 & 78 & 50 & 106 \\
\hline 13 & & 46 & 77 & 67 & 103 \\
\hline 13 & 23 & 35 & 130 & & \\
\hline 13 & 17 & 54 & 56 & & \\
\hline 14 & ND & 61 & 75 & ND & 11 \\
\hline 14 & $\mathrm{ND}$ & 51 & 34 & ND & 27 \\
\hline 14 & 11 & 63 & 858 & & \\
\hline 14 & 43 & 147 & 738 & & \\
\hline 15 & 39 & ND & 153 & ND & 32 \\
\hline 15 & 252 & ND & 131 & ND & ND \\
\hline 15 & & 57 & 115 & $6 \mathrm{l}$ & 97 \\
\hline 15 & & 45 & 22 & 20 & 25 \\
\hline 16 & ND & 369 & 97 & 6 & 5 \\
\hline 16 & 57 & 65 & 487 & & \\
\hline 17 & ND & ND & 145 & 48 & 95 \\
\hline 18 & 111 & ND & 271 & 39 & 115 \\
\hline
\end{tabular}

$1 \mathrm{~T}$ : testosterone. $\Delta$ : androstenedione. $\mathrm{D}$ : dehydroepiandrosterone. AS: androsterone sulfate. DS: dehydroepiandrosterone sulfate.

2 A pool of several plasmas.

${ }^{3} \mathrm{ND}$ : none detectable. plasma androgens in the 9-18-year-old group except in the case of $\Delta$ which did not change. The greatest increases were in D, DS and AS. The increase in testosterone is reflected in an extension of the upper limit of the $50 \%$ median range, whereas the lower limit remained at zero (ND).

\section{Discussion}

The primary sources of the androgens in the adult are the gonads and the adrenal cortex. In the male, $T$ is principally of testicular origin, $\Delta$ is secreted by both the testis and the adrenal, and D and DS are products of the adrenal cortex $[2,11]$. The female adrenal secretes the same steroids as the male adrenal, but the ovary secretes mostly $\Delta$ and a small amount of $\mathrm{T}[6]$; however, approximately $60 \%$ of the $\mathrm{T}$ in female plasma is the result of peripheral conversion of $\Delta[7]$. These relations are summarized in Table IV.

The production rates of $T$ and $\Delta$ in an adult female are 1.5 and $8.1 \mathrm{mg} /$ day, respectively, whereas the corresponding values in a male are 6.2 and $7.4 \mathrm{mg} /$ day, respectively [7]. Production rates of $\mathrm{D}$ are 7.4 and 6.6 $\mathrm{mg} /$ day for females and males, respectively, whereas the DS rate was $6.9 \mathrm{mg} /$ day for both [8].

The steroidal androgens vary widely in biologic activity, with $T$ being at least 5-10 times more potent than any other [3]. Conjugated androgens have not been tested but, by analogy with estrone sulfate (Premarin), are presumably active since the sulfate group is readily hydrolyzed in vivo.

As a group, the androgens are excreted as 17-ketosteroids. Should a specific steroid, such as testosterone, be produced in a female at a rate comparable to a male, the physiologic effect would be readily apparent but the 17-ketosteroid level in the urine would not be markedly changed. Even in a male, a doubling or tripling of the testerone production rate would not alter the 17-ketosteroid output in the urine to a level outside of the normal range. The much smaller body mass and lower levels of all hormones in children would greatly accentuate the effect of abnormal hormone production. Therefore, the determination of plasma androgen concentrations in normal children is a prerequisite to its use in differential diagnosis of children suffering from apparent endocrinopathies.

We realize that the discussion of androgen sources and production rates is based on data obtained only from adult subjects. The dearth of information from younger subjects forces a certain degree of extrapolation. Whether the gonads of prepubertal children are 
Table III. Plasma androgen concentrations ${ }^{1}$

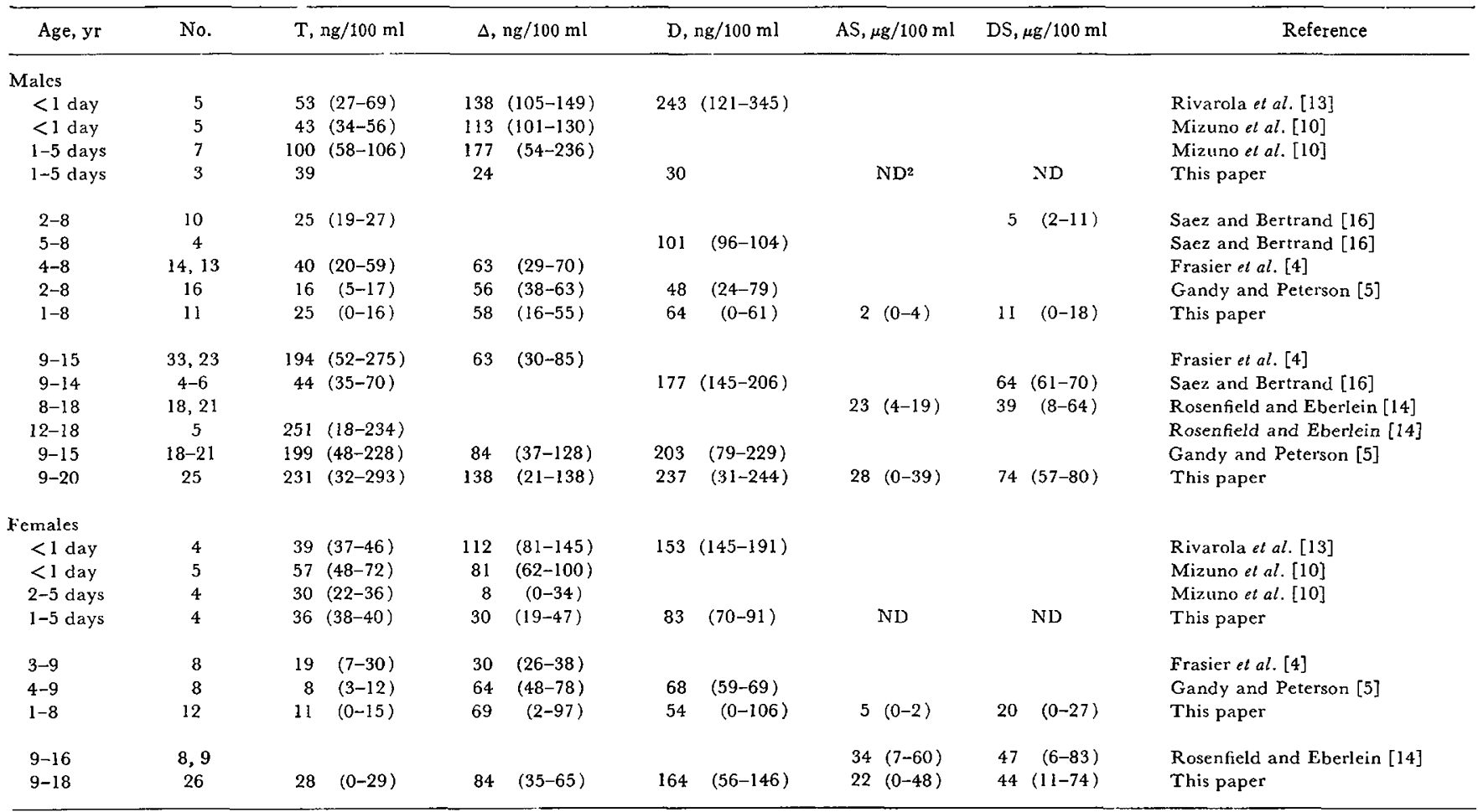

$\mathrm{X}$ : testerone. $\Delta$ : androstenedione. $\mathrm{D}$ : dehydroepiandrosterone. AS : androsterone sulfate.

DS : dehydroepiandrosterone sulfate. The mean of all values and, in parentheses, the median $50 \%$ range are shown.

ND: none detectable.

truly quiescent with regard to steroid metabolism is a subject still to be investigated.

Because of the difficulty in obtaining sizable blood samples from newborn infants, few values have been reported. Mizuno et al. [10] studied 11 babies and we have studied 7 , all pools from many persons. The former study was not performed on normal babies, but on those about to undergo exchange transfusion for blood type incompatibility. More studies have been performed on umbilical cord blood (Rivarola et al. [13], Mizuno et al. [10]). All three androgens appear to be elevated in both sexes (relative to the 1-8year-old group) when cord blood is examined.

Resko et al. [12] have shown that in rats there is a parallel to the phenomenon of high androgen concentrations in babies. They showed that the concentration of $\mathrm{T}$ in $\mathrm{l}$-day-old male rats was $10 \mathrm{ng} / 100 \mathrm{ml}$ which dropped to $3 \mathrm{ng} / 100 \mathrm{mI}$ at 10 days and then increased gradually to the adult level (a maximum of $53 \mathrm{ng} / 100$ $\mathrm{ml}$ in their series). No $\Delta$, however, was detectable until 30 days of age.

In the 1-8-year-old range, our values for androgens are in excellent agreement with those of Gandy and Peterson [5], but lower for $\mathrm{T}$ than those of Saez and
Bertrand [16] and of Frasier et al. [4]. Our DS values in males, however, are in agreement with those reported by Saez and Bertrand [16]. All three unconjugated androgens are apparently lower in the 1-8-yearold age group than in either the neonatal or older children, whereas the conjugated androgens, which were undetectable in the neonatal group, begin to appear sporadically.

As puberty approaches, androgen concentrations in all categories increase dramatically, but not necessarily evenly, in male plasma about 2 years before clinical manifestations become evident. In the case of the females, the principal increase occurs in the conjugated androgens with only a small (and perhaps questionable) increase in $\mathrm{T}$ and $\mathrm{D}$. From Table III it can be seen that there is general agreement on the values for the 9-18-year-old males $[4,5,14,16]$ except for the $T$ values of Saez and Bertrand [16]. Apparently ours is the first report of unconjugated androgen concentrations in the adolescent female.

The 9-18-year-old males exhibited quite wide ranges of $\mathrm{T}$ and $\mathrm{D}$ (Fig. 1, Table III). We have observed the same phenomenon with adult males. For example, in 37 determinations of $\mathrm{T}$ on 10 men, a range of $20-795$ 

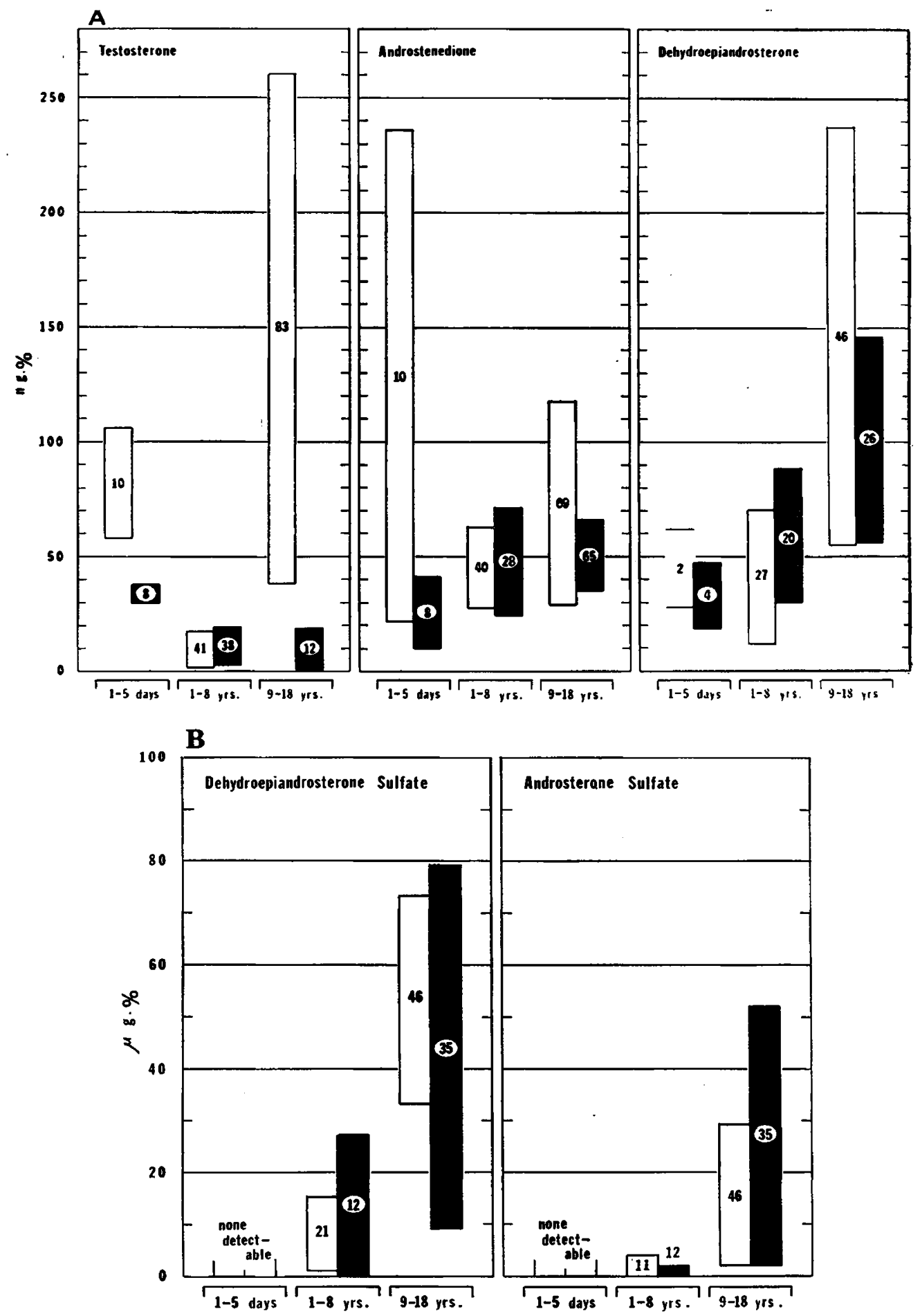

Fig. 1. $A$ and $B$ : best estimates of median $50 \%$ range of plasma androgen concentrations in children. The values were obtained by averaging most of the values shown in Table III, omitting only those in which the results of one investigator were obviously different from those of two or more investigators. Where only two investigators disagreed, both results are included; this leads to an unrealistically large range in the case of androstenedione for 1-5-day-old boys. The numbers within the bars are the number of determinations falling in that range. The open bars represent male values, the solid bars female values. 
Table IV. Summary of relative direct contribution of steroidproducing organs to plasma concentration of hormone

\begin{tabular}{|c|c|c|c|}
\hline \multirow[b]{2}{*}{ Hormone } & \multicolumn{3}{|c|}{ Organ } \\
\hline & $\begin{array}{l}\text { Adrenal } \\
\text { Cortex }\end{array}$ & Ovary & Testes \\
\hline Testosterone & ? & + & $++t$ \\
\hline Androstenedione & + & ++ & + \\
\hline Dehydroepiandrosterone & +++ & & \\
\hline $\begin{array}{l}\text { Dehydroepiandrosterone } \\
\text { sulfate }\end{array}$ & +++ & & + \\
\hline
\end{tabular}

$\mathrm{ng} / 100 \mathrm{ml}$, with a mean of $175 \mathrm{ng} / 100 \mathrm{ml}$ and a $50 \%$ median range of $70-195 \mathrm{ng} / 100 \mathrm{ml}$, was found [1]. Similarly, Steeno et al. [22] have reported wide individual variations in urinary $\mathrm{D}$ in $11-15$-year-old boys.

Upon analysis of duplicate aliquots of a plasma sample, the range on the same day is within $5 \%$ of the mean value. When additional duplicates were run on subsequent weeks, the range was within $20 \%$ of the mean. As with any sophisticated microanalytic procedure, occasionally a grossly erroneous value was found and, when this was obvious, the numbers thus obtained were disregarded. Some obvious signs of error would be extremely high blank values, low recoveries of internal standard, inappropriate specific activity values for the standards, or, as once occurred, very high bromine count rates which were traced to contamination by the plasticizer from some plastic tubing which had been used in that particular assay.

Yen et al. [24] correlated testosterone and testosterone binding affinity (TBA) levels in the plasma of boys from the ages of 8 through 14 years and showed that, although the testosterone concentrations increased, the TBA decreased; thus, perhaps the lag time between initial testosterone increase and obvious puberty could be related to the amount of unbound testosterone.

In summary, both male and female neonatal humans exhibit substantial concentrations of androgens which decline with age. Sexual maturation in the male is preceded by a dramatic rise in the testosterone concentration and real, but less dramatic, increases in the other steroids. In the female, it is primarily the conjugated androgens which increase concomitantly with sexual maturation. Wide ranges of individual values preclude using a single androgen concentration value in making diagnosis; as an adjuvant to other data, however, such information can be of value.

\section{References and Notes}

1. Boon, D. A., and Slaunwhite, W. R., JR.: Unpublished results.

2. Chapdelaine, A., MacDonald, P. C., Gonzalez, O., Gurpide,
E., Vande Wiele, R. L., and Lieberman, S.: Studies on the secretion and interconversion of the androgens. IV. Quantitative results in a man whose adrenal and gonadal function were altered experimentally. J. Clin. Endocrinol. Metab., 25: 1569 (1965).

3. Dorfman, R. I., And Shipley, R. A.: Androgens. (John Wiley and Sons, New York, 1956).

4. Frasier, S. D., Gafford, F., AND Horton, R.: Plasma androgens in childhood and adolescence. J. Clin. Endocrinol. Metab., 29: 1404 (1969).

5. Gandy, H. M., And Peterson, R. E.: Measurement of testosterone and 17 -ketosteroids in plasma by the double isotope dilution derivative technique. J. Clin. Endocrinol. Metab., 28: 949 (1968).

6. Horton, R., Romanoff, E., and Walker, J.: Androstenedione and testosterone in ovarian venous and peripheral plasma during ovariectomy for breast cancer. J. Clin. Endocrinol. Metab., 26: 1267 (1966).

7. Horton, R., AND TAIT, J. F.: Androstenedione production and interconversion rates measured in peripheral blood and studies on the possible site of its conversion to testosterone. J. Clin. Invest. 45: 301 (1966).

8. MacDonald, P. C., Chapdelaine, A., Gonzalez, O., Gurpide, E., Vande Wiele, R. L., AND Lieberman, S.: Studies on the secretion and interconversion of the androgens. III. Results obtained after the injection of several radioactive $\mathrm{C}_{19}$ steroids, singly or as mixtures. J. Clin. Endocrinol. Metab., 25: 1557 (1965).

9. McKenna, J., And Rippon, A. E.: The extraction of plasma 3-hydroxy-17-oxosteroid sulphates and the measurement of the constituent dehydroepiandrosterone and androsterone sulphate. Biochem. J., 95: 107 (1965).

10. Mizuno, M., Lobotsky, J., Lloyd, C. W., Kyobayashi, T., and MURASAWA, Y.: Plasma androstenedione and testosterone during pregnancy and in the newborn. J. Clin. Endocrinol. Metab., 28: 1133 (1968).

11. Prunty, F. T. G.: Androgen metabolism in man. Some current concepts. Brit. Med. J., 2: 605 (1966).

12. Resko, J. A., FEDER, H. H., AND GoY, R. W.: Androgen concentrations in plasma and testis of developing rats. J. Endocrinol., 40: 485 (1968).

13. Rivarola, M. A., Forest, M, G., And Migeon, C. J.: Testosterone, androstenedione and dehydroepiandrosterone in plasma during pregnancy and at delivery: concentration and protein binding. J. Clin. Endocrinol. Metab., 28: 34 (1968).

14. Rosenfield, R. L., and Ebertein, W. R.: Plasma 17-ketosteroid levels during adolescence. J. Pediat., 74: 932 (1969).

15. Rosenfiet.d, R. S., ANd Hellman, L.: Measurement of solvolyzable esters of androsterone and dehydroisoandrosterone in human plasma. Steroids, 14: 675 (1969).

16. Saez, J. M., and Bertrand, J.: Studies on testicular function in children: plasma concentrations of testosterone, dehydroepiandrosterone and its sulfate before and after stimulation with human chorionic gonadotrophin. Steroids, 12: 749 (1968).

17. Saez, J. M., Rivarola, M. A., and Mxgeon, C. J.: Studies of androgens in patients with adrenocortical tumors. J. Clin. Endocrinol. Metab., 27: 615 (1967).

18. Sandberg, D. H., Ahmad, N., Zachman, M., and Cleveland, W. W.: Measurement of plasma 11-deoxy-17-ketosteroid sulfates by gas-liquid chromatography. Steroids, 6: 777 (1965). 
19. Saroff, J., Keenan, R. E., Sandberg, A. A., and Slaunwhite, W. R., JR.: Determination of testosterone, androstenedione and dehydroepiandrosterone in human plasma using bromine-82. Steroids, 10: 15 (1967).

20. Sjovall, J., AND Vihko, R.: Determination of androsterone and dehydroepiandrosterone sulfates in human serum by gas-liquid chromatogrophy. Steroids, 6: 597 (1965).

21. Slaunwhite, W. R., JR., ANd Nefry, L.: Analysis of estrogens with bromine-82. Anal. Biochem., 5: 133 (1963).

22. Steeno, O., Heyns, W., Van Baflen, H., Van Herle, A., and DE Moor, P.: Urinary steroid excretion in normal pubertal boys. Eur. J. Steroids, 2: 273 (1967)

23. Wang, D. Y., Bulbrook, R. D., Thomas, B. S., And Friedman, M.: Determination of solvolyzed sulphate esters of dehydroepiandrosterone and androsterone in human peripheral plasma by gas-liquid chromatography. J. Endocrinol. Metab., 42: 567 (1968).
24. Yen, S., Vicic, W., Wieland, R., and Pohlman, G.: Gonadotrophin and testosterone levels in puberty. Abstract of the 5lst Meeting of the Endocrine Society, June, 1969, p. 37.

25. The technical assistance of Mr. Robert Oliver, Mrs. Rosemary Klein, Mrs. Mary Ellen Petri, Mr. Robert Ehrke and Mr. Gordon Beckhorn is gratefully acknowledged.

26. The gas chromatographic procedure was developed with the assistance of Mrs. Sandra Susten and was carried out by $\mathbf{M r}$. Elek Karsay at the Roswell Park Memorial Institute.

27. Presented in part at the Third International Congress of Endocrinology, Mexico City, Mexico, July 2, 1968.

28. Supported in part by Public Health Service Research Grant no. CA-11791.

29. Requests for reprints should be addressed to: Donald A. BooN, PH.D. Endocrine Laboratories, Children's Hospital, 219 Bryant Street, Buffalo, N. Y. 14222 (USA).

30. Accepted for publication May 21, 1971. 